\title{
EL RETRATO DE UNA MUJER DE SU ÉPOCA EN LOS EMBLEMAS MORALES DE SEBASTIÁN DE COVARRUBIAS (1610)
}

\author{
THE PORTRAIT OF A WOMAN OF HER TIME IN THE EMBLEMAS MORALES \\ DE SEBASTIÁN DE COVARRUBIAS (1610)
}

María del Mar Agudo Romeo

Universidad de Zaragoza

\begin{abstract}
This study shows the kind of woman that Sebastián de Covarrubias Orozco portrays in his Emblemas morales (1610). After a brief introduction and presentation of the author and his work, taking into account the different emblems in which a woman appears, this article studies women in general and, especially, their situation as nubile or married women, emphasizing the institutions of marriage and motherhood, with particular attention to women's participation in the education of their children; the last two sections focus on love as a passion and on beauty, respectively.
\end{abstract}

KEYWORDS: Woman; Emblems; Sebastián de Covarrubias.

RESUMEN • En este trabajo se muestra qué tipo de mujer retrata Sebastián de Covarrubias Orozco en sus Emblemas morales (1610). Tras una breve introducción y presentación del autor y su obra, teniendo en cuenta los distintos emblemas en que aparece la mujer, se estudia a la mujer en general y, especialmente, su situación como mujer núbil, casada, haciéndose hincapié en la institución del matrimonio, y madre, con particular atención a su participación en la educación de los hijos; los dos últimos apartados se centran en el amor como pasión y en la belleza, respectivamente.

PALABRAS CLAVES: Mujer; Emblemas; Sebastián de Covarrubias. 
En este trabajo se intenta mostrar qué tipo de mujer retrata Sebastián de Covarrubias Orozco en sus Emblemas morales. Para ello se examinan aquellos que tienen a ésta como protagonista o se relacionan con ella. Se han distribuido en distintos apartados, teniendo en cuenta la materia tratada, así tras esta breve introducción y presentación del autor y su obra, se estudia a la mujer en general y el único caso en que se refiere a una mujer de época, la barbuda de Peñaranda; luego se examina, especialmente, su situación como mujer núbil, casada, haciéndose hincapié en la institución del matrimonio, y madre, con particular atención a su participación en la educación de los hijos; otro apartado se centra en relaciones con varones habidas fuera del matrimonio, y, finalmente, se tiene en cuenta el tema de la belleza. Se concluye el estudio con las conclusiones y la bibliografía.

\section{EL AUTOR Y SU OBRA}

Nuestro autor nace en el año 1539 en Toledo, dentro de una familia cuyos componentes sobresalen en la vida política, eclesiástica e intelectual. Su padre, Sebastián de Horozco, aunque estudió derecho en Salamanca, ejerció como abogado en Toledo, ${ }^{1}$ donde desempeñó distintos cargos, y además se dedicó a la literatura, entre cuyas obras podemos destacar Teatro Universal de los Proverbios. Su madre, María Valero Covarrubias, pertenecía a una familia importante de arquitectos. Personajes destacados en su época fueron sus tíos Diego y Alonso de Covarrubias de Leyva; el más joven, Alonso, fue auditor de la Chancillería de Granada, asesor en el concilio de Trento, y maestrescuela y canónigo de la catedral de Toledo, amigo del Greco, fue un gran conocedor del griego y del latín. Diego, famoso escritor jurista y teólogo, fue profesor en la Universidad de Salamanca y participó también en el concilio de Trento; asimismo, fue obispo de Ciudad Rodrigo y Segovia y, siendo presidente del Consejo de Castilla fue nombrado obispo de Cuenca, aunque no tomó posesión, pues murió antes; a su tío Diego le dedica nuestro autor uno de sus emblemas. ${ }^{2}$ Finalmente, señalamos a su hermana Catalina y, especialmente, a su hermano Juan de Horozco, que fue obispo de Agrigento y Guadix, y que escribió, entre otras obras unos Emblemas morales, 3 que servirán de inspiración a Sebastián de Covarrubias.

Nuestro autor estudió en Salamanca; inició sus estudios universitarios de Teología, Leyes y Cánones en 1565 y los terminó en el año 1571, habiendo sido ordenado sacerdote en el año 1567. Nombrado racionero de la catedral de Salamanca, permaneció en dicho cargo hasta el año 1573. En el año 1578 fue nombrado capellán de su Majestad y, tras un viaje a Roma, Gregorio XIII lo hace canónigo de Cuenca, ciudad donde se estableció. En el año 1596 se le designó por nombramiento real para ir a Valencia para actuar en el problema de los moriscos. Hacia el año 1600 regresa a Cuenca y en el año 1613 morirá en dicha ciudad, donde será enterrado.

1. Tanto su padre, Juan de Horozco, como su madre, María de Soto, eran toledanos.

2. En concreto es el que inicia la Centuria tercera. Con anterioridad, su hermano Juan de Horozco dedicará sus Emblemas morales a este mismo personaje de su familia.

3. La primera edición en castellano de los Emblemas morales se llevó a cabo en el año 1589, en Segovia, realizándose una segunda edición en 1591. Consta de tres libros, el primero trata sobre la emblemática de forma teórica, y el segundo y el tercero, acogen cincuenta emblemas cada uno. Una edición en latín, Emblemata Moralia, se hizo en el año 1601, en la ciudad siciliana de Agrigento, añadiéndose dos libros más, con cincuenta emblemas cada uno. 
Aunque escribió otras obras, ${ }^{4}$ las más importantes que se conservan son los emblemas que son objeto de este trabajo, y su Tesoro de la lengua castellana o española, su obra más conocida, que publicó Luis Sánchez en 1611. Los Emblemas morales fueron publicados por el mismo Luis Sánchez en Madrid, un año antes que su diccionario, es decir, en 1610, y están dedicados al duque de Lerma. Nuestro autor aparece en la edición como capellán del rey, maestrescuela y canónigo de Cuenca y consultor del Santo Oficio, igual que se documenta en su Tesoro de la lengua. Se compone de trescientos emblemas que distribuye en tres centurias; cada uno de ellos consta, en el recto de la hoja, de un mote o lema, un grabado o pictura y un epigrama, compuesto por una octava real en todos los emblemas, y en el verso de la hoja aparece un comentario en prosa.

\section{LA MUJER EN GENERAL. LA MULIER FORTIS. LA BARBUDA DE PEÑARANDA}

El primer emblema que se va a tener en cuenta es la cent. II, emb. 47 [fig. 1] en cuya pictura, según indica en la glosa el propio Covarrubias, aparece una mujer sobre una concha, llevando en su mano un vaso de fuego, con el mote griego "Kaka tria» (tres males). En el epigrama, compuesto por una octava real como en el resto de los emblemas, señala que las tres cosas malas y dañosas son el mar, el fuego y la mujer, a la que considera un mal necesario para muchos. No obstante, a pesar de esta afirmación general de la maldad de las mujeres en la glosa dice que no es amigo de ultrajarlas y que a pesar de este

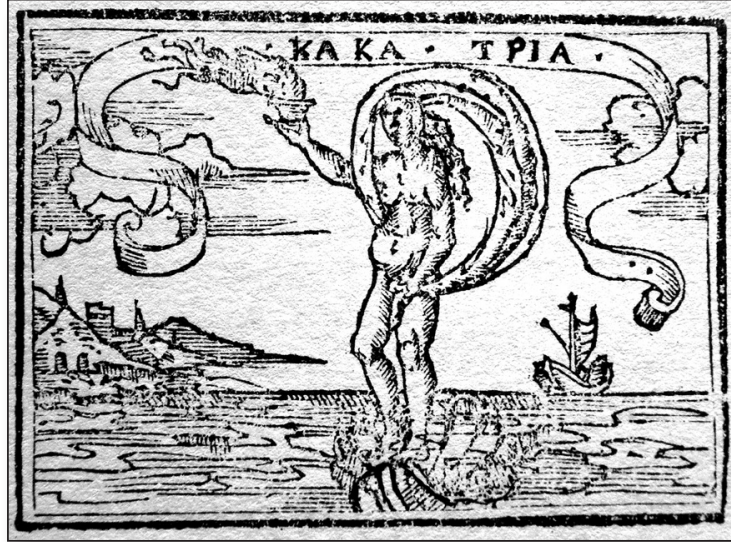

Fig. 1. Sebastián de Covarrubias, Emblemas morales. Cent. II, emb. 47. proverbio u otros semejantes existen mujeres buenas y dignas de ser celebradas con eterna memoria.

Frente a la idea tradicional de la debilidad de la mujer, nuestro autor pone reparos a ello en la cent. III, emb. 49 [fig. 2], en cuyo grabado muestra al personaje bíblico de Judit con la cabeza de Holofernes y el lema «Dux foemina facti». En el epigrama resalta cómo la mujer aunque esté sometida al varón, presenta un gran valor y fortaleza. En la glosa señala que a pesar de ser tenido por frágil el sexo femenino, ha habido muchas mujeres que han sobresalido como cualquier hombre en armas, letras, en valor y en consejo, incluso gobernando reinas, y las significa con la antes mencionada Judit, la mulier fortis quizá más representada, que según el relato bíblico salvó a Israel, su pueblo, cortándole la cabeza al general Holofernes. Su hermano Juan de Horozco también representa a esta mujer en sus emblemas, así en V, 25 la pictura muestra a Judit junto a Holofernes, con el mote "Ut fortia queque

4. Se tienen noticias especialmente de un Tratado de Cifras y de una traducción de las Sátiras, Epístolas y Arte poética de Horacio, pero no se conservan.

IMAGO, NÚM. I0, 2018, 53-73 
confundat» (para confundir a lo más fuerte), y le sirve para alabar la fortaleza de la mujer, pero no lo hace con la amplitud de miras con que lo hace su hermano; Juan de Horozco considera que es digno de admiración que en Judit, una mujer, se halle tal fortaleza de ánimo cual apenas le fue concedido a un hombre muy valeroso; termina diciendo que Dios a menudo elige las cosas pequeñas para confundir a las más fuertes. No hace ninguna mención sobre las actividades que puede realizar la mujer, aunque sean consideradas propias del varón, y además la idea de que Dios se vale de las cosas pequeñas

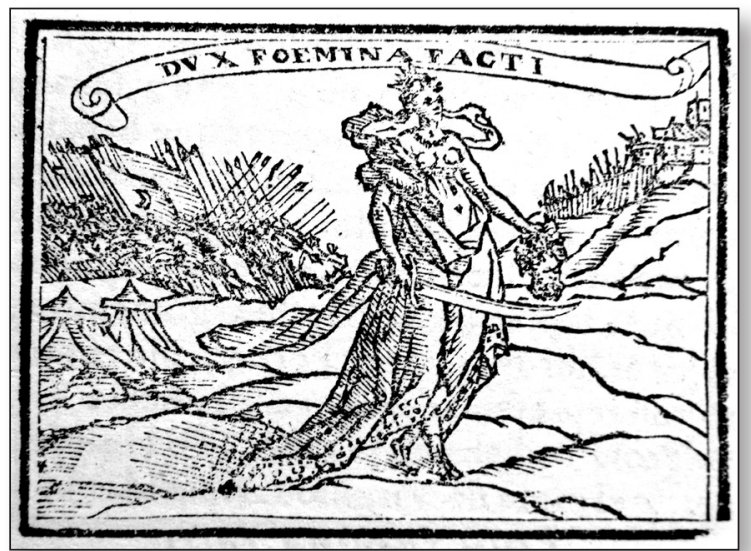

Fig. 2. Sebastián de Covarrubias, Emblemas morales. Cent III, emb. 49. para confundir a los más fuertes nos lleva pensar que considera a la mujer como un ser inferior, de hecho en la glosa de la edición castellana del emblema III, 36 ve de forma muy peyorativa el que la mujer quiera gobernar, pues considera que ha nacido para ser gobernada. Covarrubias en la cent. II, emb. 50 censura a quienes se dejan influir por mujeres, amigos y criados.

El mote «Dux foemina facti» (una mujer es guía de la hazaña), como señala el propio autor en la glosa, pertenece a Virgilio, Eneida I, 364, y se refiere a Dido, que fue reina de Cartago, una figura ilustre de la antigüedad clásica que tuvo un destino triste a pesar de ser considerada fundadora y gobernadora de una ciudad que fue cabeza de un gran imperio antes de sucumbir ante el poder de los romanos. Viuda por la muerte de su marido a manos de su propio hermano, huye de su país para fundar Cartago, donde arribará Eneas de quien se enamora; abandonada por éste se suicida.

Termino este apartado con la cent. II, emb. 64 [fig. 3] que Covarrubias dedica al tema del hermafrodito. Este emblema, con el lema "Neutrumque et utrumque» (ni una cosa ni la otra y ambas), que toma de Ovidio, Metamorfosis IV, 379, donde se narra la historia de Hermafrodito, ${ }^{5}$ al que se refiere nuestro autor en el epigrama y en la glosa, le da pie para mencionar a una mujer real de su época, ${ }^{6}$ al decir al final de la

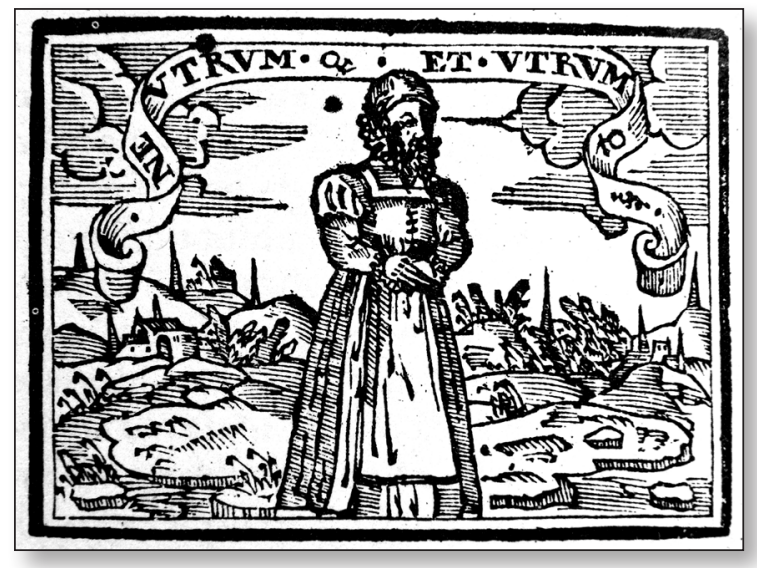

Fig. 3. Sebastián de Covarrubias, Emblemas morales. Cent. II, emb. 64.

5. Nec duo sunt sed forma duplex, nec femina dici / nec puer ut possit, neutrumque et utrumque uidetur (no son ya dos, sino una forma doble, y no podría decirse que es una mujer ni un muchacho y las dos cosas parecen), Metamorfosis, IV, 378-379, ed. y trad. de A. Ruiz de Elvira [1964].

6. Juan de Horozco también presentará a un personaje femenino de la época, pero muy diferente, en concreto el emb. IV, 22, lo dedica a santa Teresa, a la que considera raro ejemplo de santidad y religiosidad en su época. 
glosa que la figura es el retrato de la barbuda de Peñaranda, sin dar ningún dato más. Su nombre era Brígida del Río y alcanzó gran popularidad, lo que le llevó a la corte de Felipe II y luego al reino de Valencia. En el año 1590 la retrató el pintor toledano Luis Sánchez Cotán, cuadro actualmente depositado en el Museo del Prado, que sirvió como modelo a nuestro autor para el retrato que de la misma presenta en la pictura, donde se ve a un personaje vestido de mujer pero con barba. ${ }^{7}$ Nuestro autor también la cita en su Tesoro de la lengua, cuando en la voz «barba», dice que ésta distingue en lo exterior al hombre de la mujer, pero que hay excepciones y entre ellas cita a la barbuda de Peñaranda; también recoge el proverbio: "A la mujer barbuda, de lejos la saluda».

\section{LA DONCELLA. LA HIJA}

Poco es lo que nos dice nuestro autor sobre la mujer núbil. En dos de los emblemas que se van a ver, aparece la doncella en un estado que antecede al de mujer casada, el papel fundamental de la mujer de su época, tal como documenta también en nuestros emblemas; en un tercero se muestra un ejemplo de mala hija. La cent. I, emb. 5 [fig. 4], está dedicado a la flor virginal, a la que ensalza en el epigrama, en el que también exhorta a los pechos virginales a no perderla, pues no puede ser reparada, haciendo alusión a ello el mote "Nulla reparabilis arte», ${ }^{8}$ que forma parte de un dístico elegiaco de una de

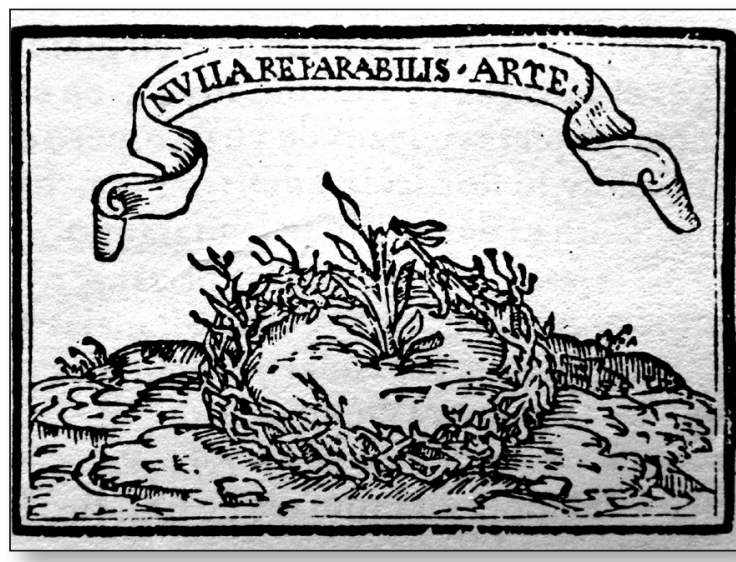

Fig. 4. Sebastián de Covarrubias, Emblemas morales. Cent. I, emb. 5 . las Heroínas de Ovidio, en concreto la carta que Enone, ninfa de una fuente, dirige a Paris, que la ha abandonado por Elena; en el texto en que se inserta nuestro lema, le dice que no se prometa fidelidad de la laconia y que se lamentará como lo hace el menor de los Atridas, pues con ningún arte se puede reparar la honra cuando es lesionada, pues muere de una vez. En la glosa Covarrubias compara la virginidad con la azucena, que considera que es su símbolo, y en la pictura, según dice en la misma glosa, «se pinta rodeada de un seto, pero desportillado y su flor lacia y destroncada». El pensamiento lo toma de la composición 62 de Catulo, que es un epitalamio o canto de bodas, donde un grupo de muchachas alterna con un grupo de muchachos; el texto que le inspira corresponde a las muchachas, donde comparan a la joven virgen con la flor que nace en un jardín secreto, ignorada por el rebaño y no tocada por el arado, a la que el sol da vigor y la lluvia la nutre, deseada por jóvenes y doncellas, pero que al ser cortada por la punta

7. Muy conocida es también la pintura de otra mujer barbuda, en concreto la que José Ribera hizo a Magdalena Ventura, natural de la región italiana de los Abruzzos, que aparece junto a su marido y amamantando a su tercer hijo.

8. Nulla reparabilis arte laesa pudicitia est, (con ningún artificio se puede reparar el pudor lesionado), Ovidio, Enone a Paris, 103-104, ed. y trad. F. Moya [1986].

IMAGO, NÚM. 10, 20।8, 53-73 
de la uña deja de ser deseada, como le sucede a la joven que pierde la flor de la castidad. ${ }^{9}$ A continuación siguen los muchachos refiriéndose al matrimonio con el símil del olmo y la vid, considerando la situación de la mujer casada mejor que la de la joven virgen, cuando ya ha llegado a madurar. Termina el epitalamio con la exhortación a la novia de someterse al marido, a quien la entregó su padre junto con su madre, a quienes debe obedecer; asimismo se señala que su virginidad no es solo suya, sino que una parte es de su padre, otra parte es de su madre y solo la tercera parte es suya; esta idea no se halla en ninguna otra fuente latina. Covarrubias también señala en la glosa que L. Ariosto imita la obra de Catulo con sus poemas, en concreto escribe el que empieza La virginella è simile alla rosa, ${ }^{10}$ donde podemos observar que habla de la rosa, frente al genérico flor, que se halla en Catulo, y azucena que

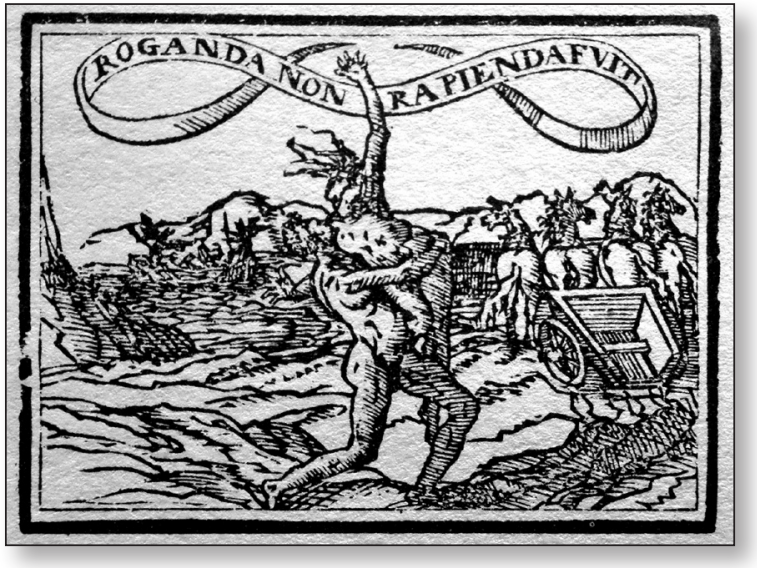

Fig. 5. Sebastián de Covarrubias, Emblemas morales. Cent. II, emb. 39. utiliza nuestro autor, que es símbolo de la virginidad y de la Virgen María.

La cent. II, emb. 39 [fig. 5], presenta en cierta manera, como en Catulo, la idea de que el padre y la madre entregan a la joven al marido. Luis Vives, por otra parte, también considera que nadie mejor que el padre para encontrar un marido apropiado para la hija. En concreto, Covarrubias critica en dicho emblema a quien rapta a una mujer sin su consentimiento en vez de pedírsela al padre; en la glosa se puede observar que en la época de nuestro autor era una práctica no inusual, pues tal como indica existen leyes tanto civiles como canónicas que castigaban esas conductas. En el grabado se representa el rapto de Proserpina por parte de Plutón que la lleva en sus brazos, apareciendo a un lado su carro con sus caballos, con el que sube a la tierra desde su reino infernal para de nuevo regresar a él con la joven. En el epigrama se puede entender que diferencia el cortejo del rapto por la fuerza sin consentimiento de la joven, que considera una maldad y tiranía; pone como ejemplo de este hecho el mencionado rapto de Proserpina, igual que en el dibujo, y considera que Plutón debió pedírsela a su madre Ceres si la quería como su esposa y mujer.

Frente al hecho de que el padre eligiese el marido, como dice Luis Vives, en bien de su hija, Andrea Alciato en el emblema 197 presenta lo contrario, a saber, a un padre que arrastra a su hija a la muerte al casarla con un hombre afectado de una enfermedad contagiosa. Hernando de Soto en el emblema XXV, en el que se refiere al matrimonio forzoso, en la glosa recuerda que el Concilio de Trento considera al matrimonio como un lazo perpetuo que requiere el libre consentimiento y voluntad de los contrayentes.

La cent. II, emb. 29 [fig. 6], trata sobre aquellos que mataron a sus padres, hecho que en la glosa dice que es inconcebible. Da una serie de ejemplos de varones que dieron muerte a sus progenitores y entre ellos, sin hacer ningún comentario relativo a su condición de mu-

9. Vt flos in septis secretus nascitur hortis, éste es el verso 39 del poema de Catulo, que documenta Covarrubias. El parlamento de las muchachas incluye desde este verso 39 hasta el 48 .

10. Corresponde a Orlando furioso, I, 42. 
jer, menciona que la hija del rey Servio Tulio mató a su padre, y estando su cuerpo tendido en una calle pasó con su carro sobre él, hollándole los caballos y las ruedas. En la pictura representa la escena que se acaba de describir, con el cochero guiando el carro, y en el epigrama se refiere a esta misma acción, llamando a Tulia mal nacida, después de señalar que Solón no castigó al hijo patricida, al considerar que este hecho era inconcebible, como repite en la glosa. El mote "Scelus est odisse parentem» lo toma de Ovidio, Metamorfosis X, 314, pero no tiene relación con Tulia, ya que se documenta en el mito de Mirra que enamorada de su propio padre cometió incesto, por ello lo que Ovidio dice es que odiar a un padre es un crimen, pero amar a un padre como hace Mirra es un crimen mayor. Fuente fundamental para esta historia, aunque no se cite, es el historiador de la época de Augusto, Tito Livio, Historia de Roma desde su fundación I, 48, que cita a Tulia como instigadora de la muerte de Servio por parte de Tarquinio, su marido, y cómo deteniéndose el cochero ante el cadáver de su padre hizo que pasara el carro por encima de su cuerpo. Frente a esta acción impía de matar a un padre, en la cent. II, emb. 89, Covarrubias presenta a la cigüeña como símbolo de la piedad filial.

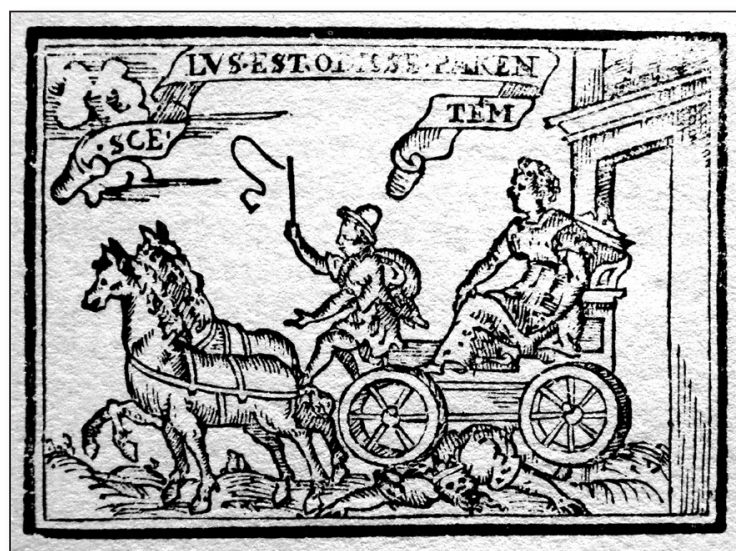

Fig. 6. Sebastián de Covarrubias, Emblemas morales. Cent. II, emb. 29.

\section{LA CASADA. \\ EL MATRIMONIO. LA VIUDA}

Nuestro autor no solo se refiere a la mujer casada sino que también trata sobre el marido y se ocupa de temas relativos al matrimonio que afectan a ambos cónyuges. A la casada dedica la cent. II, emb. 41 [fig. 7], donde, bajo el mote "Clarior absens» (más resplandeciente cuando está ausente), en la pictura aparecen la luna y el sol, simbolizando a la mujer y el marido respectivamente, comparación que se halla en Plutarco; ${ }^{11}$ el epigrama señala que la fe

\footnotetext{
11. "Vemos que la luna, cuando está lejos del sol, aparece clara y luminosa, pero que palidece y se oculta cuando el sol está cerca; la esposa sabia hace lo contrario: aparece sobre todo cuando está en compañía del marido, pero se queda en casa y no se muestra cuando él está ausente», Cuestiones matrimoniales, 9, trad. de F. Gutiérrez [2010].
}

IMAGO, NÚM. 10, 2018, 53-73 
y la lealtad de la casada reluce estando ausente su marido y que cuanto más escondida y retirada está tanto más es conocido su valor. En la glosa insiste en la idea de que el ámbito propio de la mujer es el doméstico y, sobre todo, que, cuando el marido está ausente, debe vivir retirada en su casa. Por contrapartida, en la cent. I, emb. 31, Covarrubias critica al cortesano que permanece largo tiempo fuera de su casa, gastando su salud y perdiendo su hacienda.

En dos emblemas se refiere al matrimonio, teniendo en cuenta a ambos cónyuges. En la cent. II, emb. 46 [fig. 8], bajo el mote "Pressi iugo gemuere» (oprimidos bajo el yugo gimieron), que toma de Ovidio, Metamorfosis, I, 124, representa en el dibujo a un hombre y a una mujer enlazando sus diestras, símbolo de la fidelidad en el matrimonio, y sobre ellos un yugo. En el epigrama en primer lugar habla del regocijo de los casados y de sus gentes en la celebración la boda y de los gastos, para continuar diciendo que, cuando queda el hombre solo con su nueva compañía bajo el yugo conyugal, dan más de cuatro pares de gemidos. En la glosa vuelve a referirse a las cargas que lleva consigo el matrimonio y recoge varios pensamientos cristianos relativos a él.

En la cent. II, emb. 99 [fig. 9], simboliza el matrimonio mediante dos palomas, que aparecen mordisqueándose en el dibujo, con el mote "Quae modo pugnarunt, iungunt sua rostra» (las que hace un momento lucharon, unen sus picos), que pertenece a Ovidio, Arte de Amar II, 465, y que hace alusión como en nuestro emblema a que después de las riñas entre los enamorados viene la reconciliación. ${ }^{12}$ En el epigrama compara precisamente a los casados y sus riñas con unas palomillas que tras pequeños enfrentamientos se reconcilian

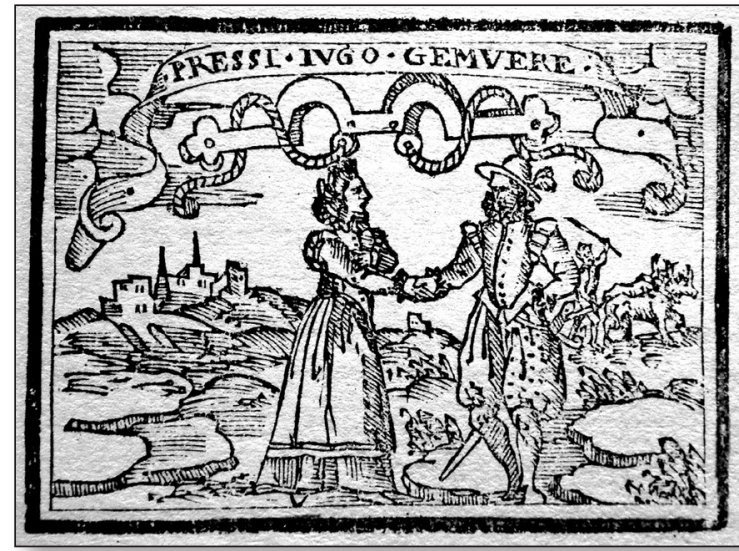

Fig. 8. Sebastián de Covarrubias, Emblemas morales. Cent. II, emb. 46.

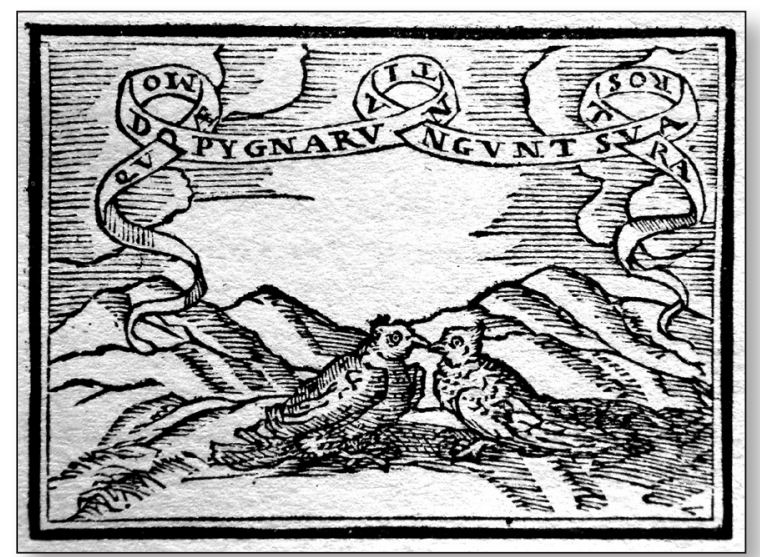

Fig. 9. Sebastián de Covarrubias, Emblemas morales. Cent. II, emb. 99. con alegría. En la glosa sigue hablando de las rencillas dentro del matrimonio y considera que si están basadas en algo grave resulta penoso y supone vivir con descontento y peligro; no obstante, aconseja que si no son

12. "Las palomas que poco ha lucharon, unen sus picos, y su arrullo está lleno de caricias y de amor», Ovidio, Arte de Amar, II, 465-466, trad. de E. Montero [2005]. 
importantes no se intervenga para poner paz, sino que se deje poner fin y hacer las paces a los casados.

Al marido se dirige en la cent. I, emb. 53 [fig. 10], donde habla del trato que debe a su mujer, sirviéndose de la albahaca para significarlo. En el grabado representa una planta de albahaca, bajo el mote «Tocada y no ahaxada», mostrándose en el epigrama partidario de que el marido trate con blandura a

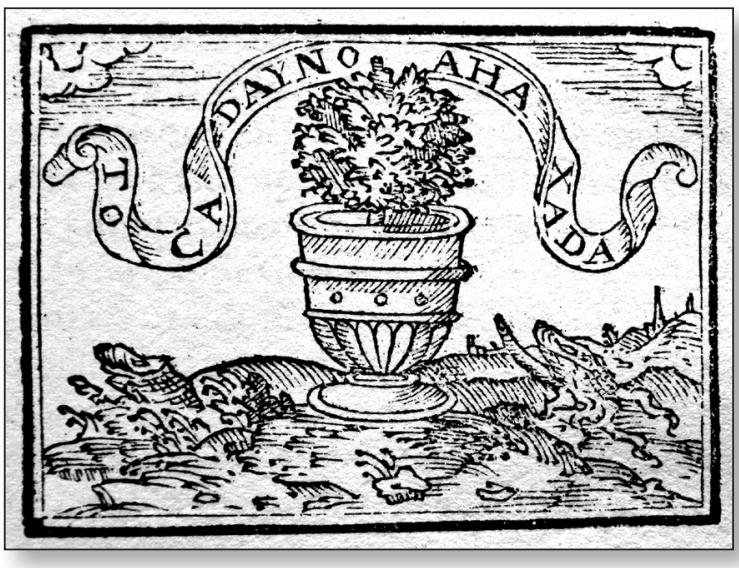

Fig. 10. Sebastián de Covarrubias, Emblemas morales. Cent. I, emb. 53.

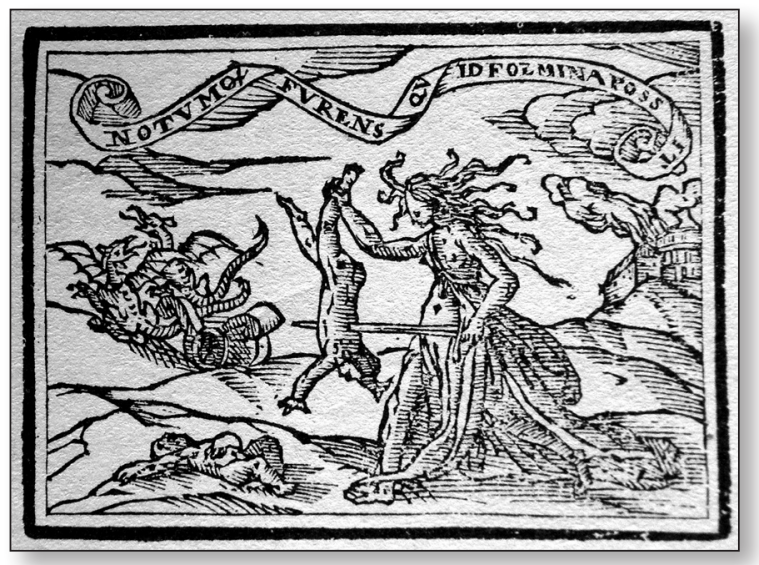

Fig. 11. Sebastián de Covarrubias, Emblemas morales. Cent. III, emb. 80 . el ejemplo de Medea, pues abandonada por Jasón, mató en venganza a sus propios hijos. Además del texto del mote, que en realidad se refiere a Dido y hace referencia a su suicidio al ser abandonada por Eneas, en la glosa recoge otro texto de Virgilio, en concreto de la Bucólica VIII, 48 ss., donde, sin nombrar a Medea, se habla de una madre cruel que mata a sus propios hijos, con alusión sin duda a ella.

la mujer. En la glosa sigue insistiendo en el buen trato del marido hacia ella, pues si la irrita se puede convertir en escorpión o víbora, animales con un significado muy negativo cuando simbolizan a la mujer.

En la cent. III, emb. 80 [fig. 11], nos dice qué puede llegar a hacer una mujer, cuando contrariada, muestra toda su furia. En el epigrama menciona que no existe furor que se iguale al de la hembra, que irritada puede llegar a matar al marido y al padre, e, incluso, desmembrar a su pequeños hijos, sirviéndose como ejemplo de la figura de Medea. Efectivamente, bajo el mote "Notumque furens quid femina possit» (sabido es qué puede hacer una mujer furiosa), que toma de Virgilio, Eneida V, 5-6, el grabado nos muestra a Medea, con el cabello revuelto como una Furia, con uno de sus hijos muerto en el suelo y con el otro pendiente de su mano mientras le clava una espada, señalándose al final del epigrama que ello no parece posible, aunque ésta fuera Alecto, Tisífone o Megera; los nombres que cita son precisamente los de las Erinias griegas con las que se identifican las Furias romanas. En la glosa muestra que cuando se contraria el amor de una mujer la saña de ésta es tan grande que su venganza le lleva a matar a los hijos para que paguen por sus padres, por lo que pone .

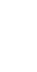




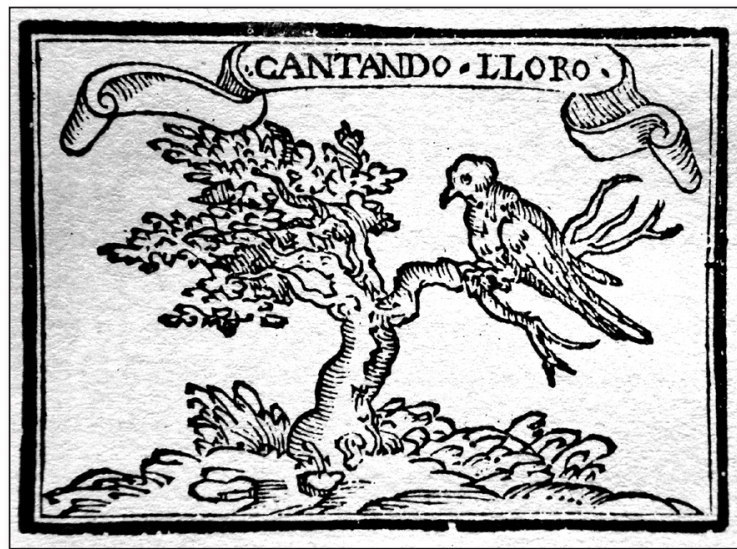

Fig. 12. Sebastián de Covarrubias, Emblemas morales. Cent. I, emb. 62 .

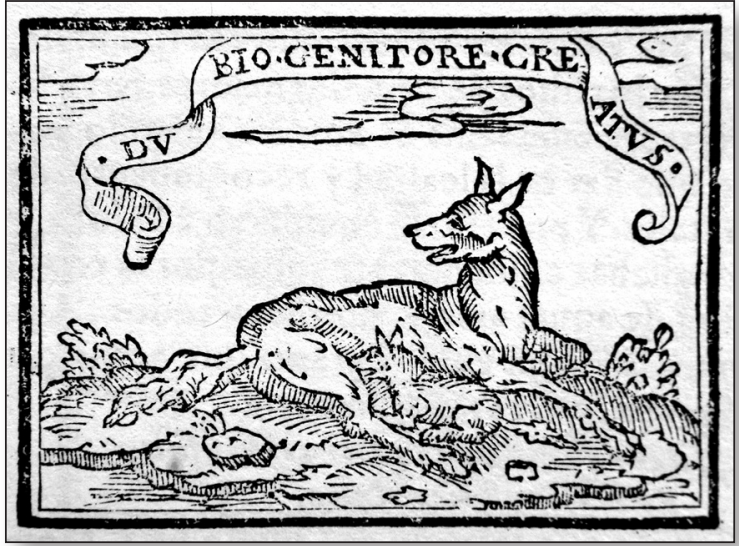

Fig. 13. Sebastián de Covarrubias, Emblemas morales. Cent. I, emb. 54.
En la glosa de la cent. I, emb. 62 [fig. 12], se dice que la tórtola es símbolo de la viuda que muerto su marido, pasa la vida en soledad, pero continúa señalando que el emblema lo aplica a los que disimulan su dolor con el lema "Cantando lloro». Efectivamente, en el grabado aparece bajo dicho mote una tórtola posada en la rama seca de un árbol. La tórtola es un ave que pertenece al orden de las palomas, que según algunos autores ${ }^{13}$ guarda fidelidad a su pareja, de manera que cuando ésta se muere no se une a otra, razón por la que se le identifica con la viuda que no se vuelve a casar.

\section{LA MADRE. LA EDUCACIÓN DE LOS HIJOS}

Si el ámbito propio de la mujer es la casa, un papel tradicional fundamental es sin duda su maternidad, el traer al mundo unos hijos especialmente dentro del matrimonio que continúen la estirpe, aunque Covarrubias se va a referir en particular a hijos habidos fuera del matrimonio de padres de una buena posición social; así en uno de sus emblemas se hace referencia a

que los hijos sean efectivamente del padre que les atribuye la madre, pero, en contrapartida, en otro critica el abandono de un hijo por parte del padre. En la cent. I, emb. 54 [fig. 13], en el grabado se representa a una loba amamantando a su lobezno, significando a la mujer promiscua sexualmente que atribuye como padre para su hijo a quien realmente no lo es, pues, según dice en el epigrama, tras unirse a varios hombres la madre busca entre todos al que mejor le cuadre a causa de la honra y del sustento que le puede proporcionar, y le da como progenitor al señor y al caballero, aunque sea hijo de su lacayo o despensero. En la glosa señala que solo es aplicable a los hijos de aquellas madres cuya libertad y ruin fama es notoria, y tienen poco que fiar en su lealtad y recogimiento. El lema «Dubio genitore creatus» (nacido de dudoso padre) lo toma de Ovidio, ${ }^{14}$ Metamorfosis V, 145. En la glosa cita asimismo

\footnotetext{
13. Así lo hace Claudio Eliano en su Historia de los Animales X, 33.

14. Ovidio lo aplica a Astreo, que es uno de los que mueren en el enfrentamiento entre Perseo y Fineo, siendo uno de los partidarios de este último, cuando quiso casarse con su sobrina Andrómeda, causa de la enemistad.
} 
un epigrama latino de Ausonio, escribiendo el inicio del mismo y los dos versos finales muy apropiados para el tema que trata. ${ }^{15}$ La composición de Ausonio recuerda uno de los episodios más conocidos de la legendaria Roma, el amamantamiento de Rómulo y Remo por una loba, que, según Tito Livio, también podría haber sido una prostituta, ${ }^{16}$ así en su obra sobre la Historia de Roma desde su fundación (I, 4 ss.) narra que el cesto en que habían sido depositados Rómulo y Remo en el agua, fue a parar a un lugar seco donde atraída por sus lloros los encontró una loba que mansamente les ofreció sus ubres; así los encontró Faustulo, mayoral del ganado del rey, que se los llevó y los entregó a su mujer Larentia para que los criara. Sin embargo, Tito Livio, como hace en diversas ocasiones al referirse a los orígenes legendarios de Roma, da otra versión y dice que algunos consideraban que esa leyenda maravillosa se debía a que Larentia prostituía su cuerpo, razón por la que los pastores la llamaban lupa. El hecho de considerar como padre al que más conviene, también lo cuenta Tito Livio en este mismo relato, pues dice que su madre, la vestal Rea Silvia, al quedar embarazada de ellos, víctima de una violación, bien porque lo creyera así, bien porque la complicidad de un dios dignificara su falta, atribuyó al dios Marte la paternidad de su sospechosa descendencia.

En la cent. II, emb. 52 [fig. 14], también presenta el tema de la paternidad, con la idea de que el padre lo sea realmente, pero aquí en vez de censurar especialmente a la mujer, censura al hombre que abandona a los hijos que son los que sufren las consecuencias. En el grabado aparece un niño con serpientes, tanto enroscadas en su cuerpo como a su alrededor, relacionado con

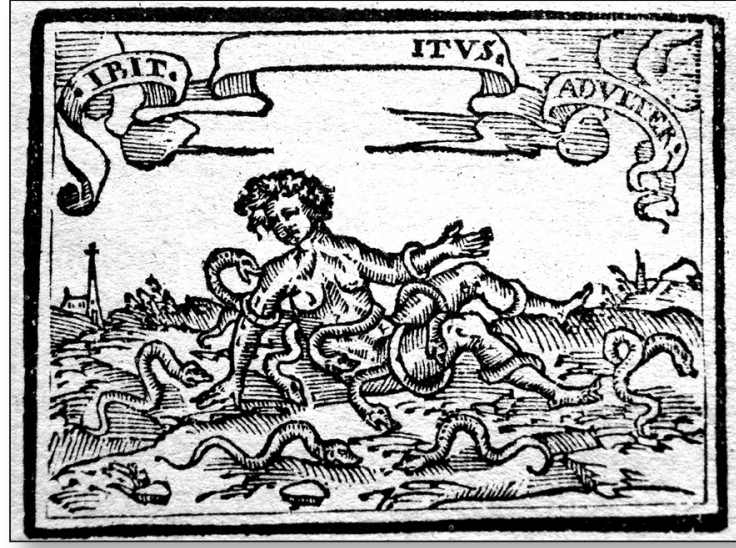

Fig. 14. Sebastián de Covarrubias, Emblemas morales. Cent. II, emb. 52. lo que se dice en el epigrama sobre la costumbre de unas gentes de África que cuando se sospecha que la mujer ha concebido de un hombre extranjero, dejan que al recién nacido le piquen las serpientes, de modo que así se vengan en el niño que no tiene culpa, en vez de castigar únicamente al huésped desleal, que es el que merece el castigo. En la glosa nos da el nombre de ese pueblo africano, los Psilos, ${ }^{17}$ y vuelve a relatar la historia, tomando como fuente a Plinio el Viejo, Historia Natural

15. En concreto Covarrubias indica: "Ausonio Galo en un epigrama: Qualem superbus, etc, dice así. Credo quod illi, nec pater certus fuit, / Et mater est vere lupa». La traducción completa del epigrama es la siguiente: "Contra un rico degenerado, hijo de un adúltero. Un hombre soberbio, rebosante de riquezas y orgullo, y sólo noble de palabra, anda despreciando los nombres ilustres de su tiempo, mientras busca antiguos linajes, convirtiendo en sus antepasados a Marte y Remo, y a Rómulo, nuestro fundador. Manda que los cubran con telas de los seres, los cincela en plata maciza, al tiempo que les pinta a la cera los umbrales de sus capillas y los nichos de los atrios. Todo me lo creo, porque ni sabe quién fue su padre y su madre es, efectivamente una loba». Este epigrama es el 45 y la traducción es de A. Alvar [1990].

16. En la lengua latina lupa además de significar «loba» puede significar también "prostituta", "mujer de vida licenciosa», según se observa ya en Plauto, Epidicus, 40: Diuortunt mores uirgini longe ac lupae (difieren con mucho las costumbres de una muchacha y de una prostituta). Entre otros autores asimismo la usan Cicerón, Ovidio y Juvenal.

17. También se refiere a este pueblo y la misma historia sobre su relación con las serpientes Lucano, en la Farsalia

IMAGO, NÚM. 10, 2018, 53-73 
VII, 2. Antes menciona que en tiempos pasados fue muy usado que los hijos que doncellas principales concebían clandestinamente, cuando los padres de ellas se enteraban, fuesen arrojados a algún desierto para que las fieras se los comiesen, aunque éstas más piadosas que los hombres los criaban. Sigue la glosa, sin duda haciendo alusión Covarrubias a su

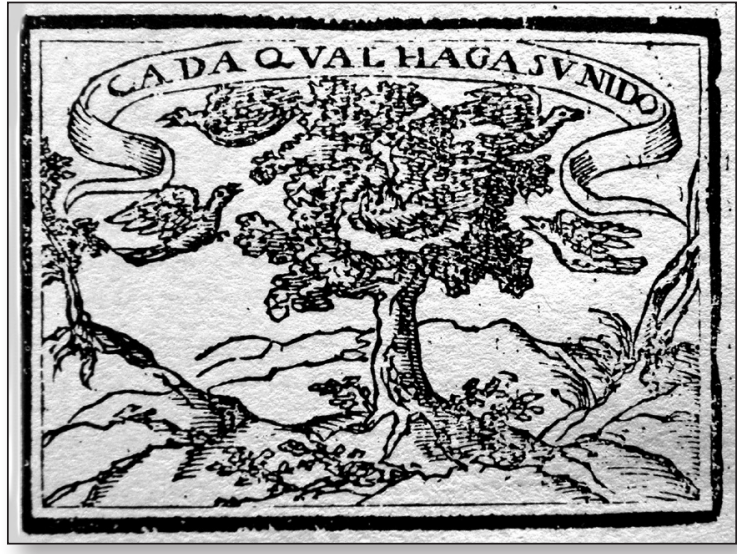

Fig. 15. Sebastián de Covarrubias, Emblemas morales. Cent. I, emb. 35 . época, que el hecho de que aquél que lo comete sea castigado como homicida o parricida, muestra la gravedad del delito, por lo cual existen lugares, hospital u obra pía, donde se acoge y cría a estos expósitos. Termina con la intención del emblema que no es otro que el de decir que paga el niño inocente y el padre adúltero queda libre, según el mote latino "Ibit impunitus adulter» (el adúltero se irá impune).

Cuando se refiere al tema de la educación de los hijos, Covarrubias habla de los padres y de las madres; en la cent. I, emb. 35 [fig. 15], bajo el lema "Cada cual haga su nido", se representa en el grabado un árbol con un nido del que salen y entran unos pájaros; en el epigrama enseña que, tras formar los padres en la religión y en la vida al hijo, éste debe despegarse de ellos, incluso aunque su madre lo quiera mucho, y lo compara con el pájaro que una vez emplumado se arroja del nido paterno y busca un lugar propio. En la glosa insiste en que los hijos que no saben apartarse del regalo de sus padres son de ánimo vil y apocado y se convierten en viciosos y holgazanes, y, entre otras cosas, difaman la honra de doncellas y mujeres muy recogidas y son alborotadores del pueblo; no obstante, la justicia no sabe cómo hacerles frente por no contrariar a sus padres y deudos, hecho que nos hace tener en cuenta que se refiere a familias con una posición destacada como hemos visto antes en los emblemas dedicados a la paternidad. Da una solución al problema y es que los mismos padres los fuercen a marcharse a Flandes, Italia y las dos Indias o al mundo en general, que es muy amplio, y donde podrán convertirse en hombres. Termina señalando de nuevo la semejanza de la

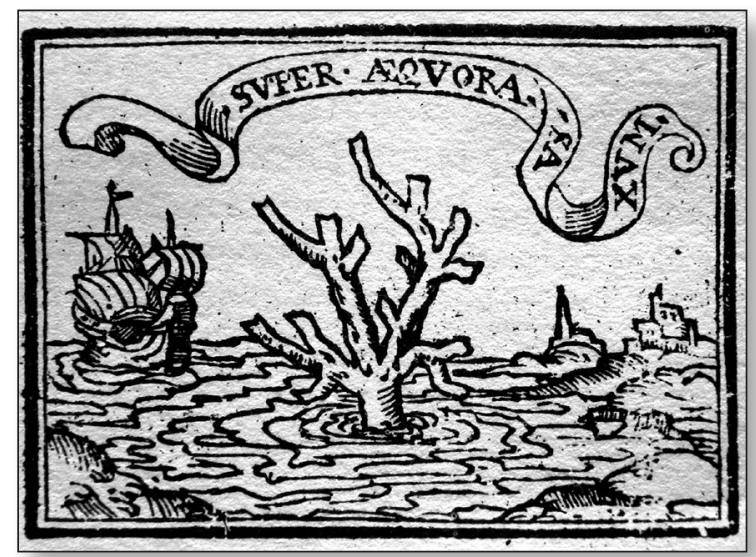

Fig. 16. Sebastián de Covarrubias, Emblemas morales. Cent. I, emb. 41 . 
marcha del hijo con la del pájaro del nido, del que son arrojados los pollos cuando van a echar a volar. ${ }^{18}$

En la cent. I, emb. 41 [fig. 16], bajo el mote "Super aequora saxum» (piedra sobre las aguas), con un grabado donde aparece en primer plano un coral en el mar delante de un barco y al fondo un faro, el epigrama compara el coral que en el mar bajo las aguas profundas es blando, pero sobre las aguas se convierte en dura piedra, con el joven que en su patria se dedica a amoríos, si se lanza al otro lado del mar. En la glosa de la misma manera en primer lugar habla del coral, citando como fuente a Teofrasto, y luego se vuelve a referir a los caballeros mozos que viven regalados de su padres, que si se les compele a salir a otros reinos se endurecen con el trabajo y cambian su condición.

En la cent. II, emb. 87 [fig. 17], insiste en lo perjudicial que es el hecho de que un padre deje a un hijo pequeño hacer todo lo que quiera. En la pic-

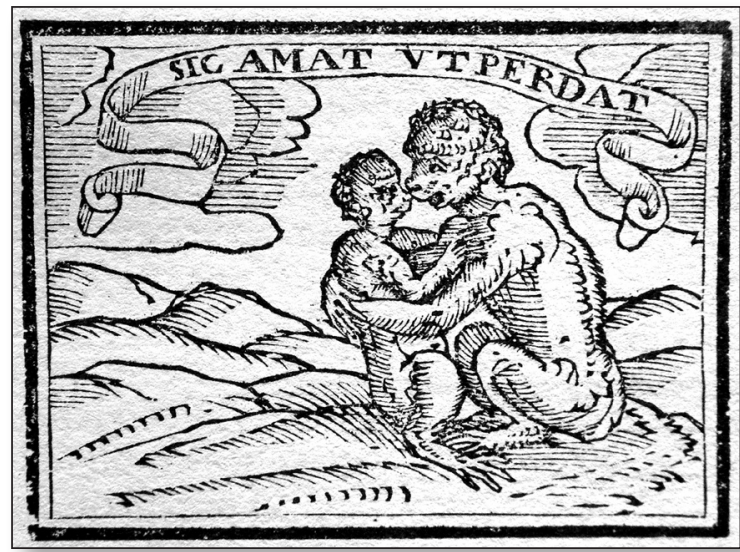

Fig. 17. Sebastián de Covarrubias, Emblemas morales. Cent. II, emb. 87. tura aparece una mona con su monillo bajo el lema "Sic amat ut perdat» (de tal manera lo ama que lo pierde), muy apropiado con lo que se dice en el epigrama, pues compara el comportamiento de los padres que educan a sus hijos con gran regalo con la mona que tantos brincos, besos y abrazos le da a su monillo que termina matándolo. En la glosa considera difícil disuadir a un padre que educa mal a su hijo, para que no lo haga, pero dice que será el tiempo el que lo desengañe, cuando siendo ya mayor el hijo, le pierda el respeto y la obediencia, dándole mil pesares y enojos y siendo una deshonra para él y para su linaje.

En el apartado anterior se ha visto un ejemplo de mala madre, el de Medea que mata a sus propios hijos, para significar qué puede hacer una mujer contrariada.

\section{LA LUJURIA. LA HECHICERA. LA RAMERA}

Se van a examinar una serie de emblemas en los que aparece la mujer, pero que en realidad van dirigidos a los varones, para que huyan de los perjuicios que ésta puede proporcionarles, refiriéndose a la lujuria, con relaciones habidas fuera del matrimonio. En efecto, Covarrubias exhorta a los hombres a huir del amor pasional, apareciendo figuras femeninas como la hechicera y la prostituta, simbolizando a esta última mediante la hiedra y la sirena, respectivamente, temas que se encuentran en otros autores de emblemas, incluido su her-

\footnotetext{
18. "Se dice que los gavilanes son duros de sentimientos para con sus hijos: cuando ven que pueden volar, no les proporcionan más comida, sino que los golpean con sus alas y los arrojan del nido", Isidoro de Sevilla, Etimologías XII, 7, 56, trad. de J. Oroz y M. A. Marcos [1994].
}

IMAGO, NÚM. 10, 2018, 53-73 


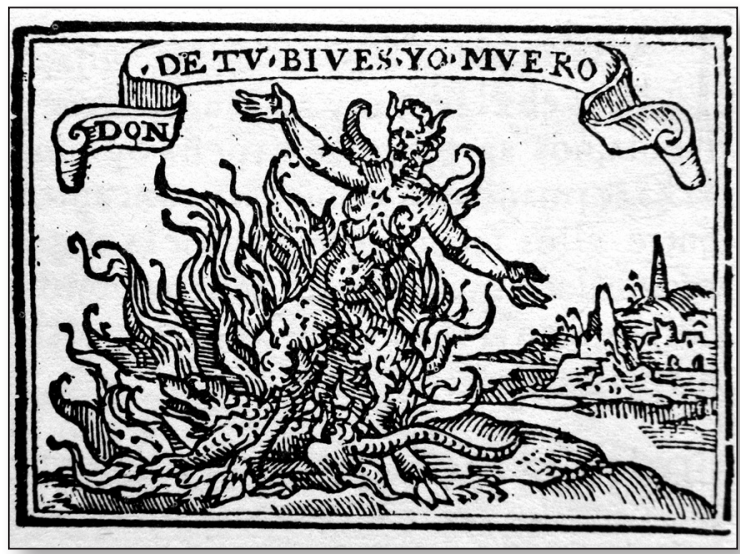

Fig. 18. Sebastián de Covarrubias, Emblemas morales. Cent.

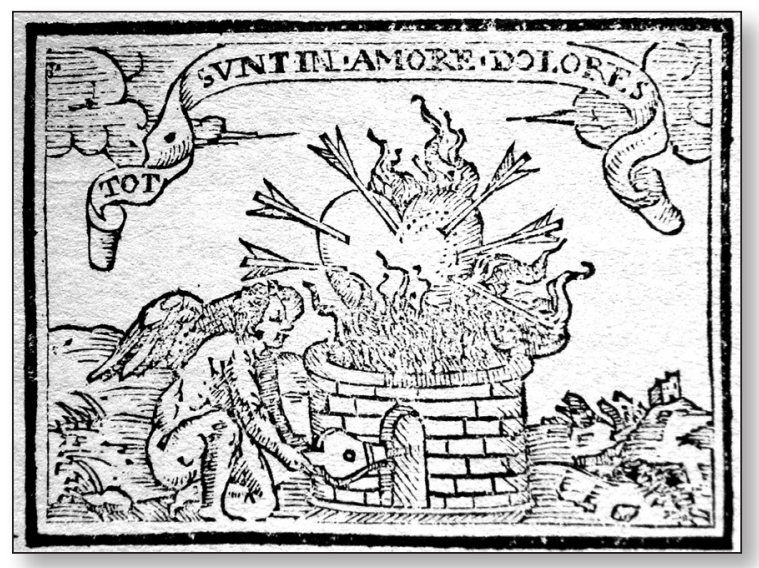

Fig. 19. Sebastián de Covarrubias, Emblemas morales. Cent. III, emb. 63. I, emb. 63.

mano Juan de Horozco, pero no hace una crítica a la existencia de la prostitución o a quienes la ejercen, sino a los males que acarrean a los hombres.

En la cent. I, emb. 63 [fig. 18], bajo el lema "Donde tú vives, yo muero», en el grabado se representa a un sátiro que se consume entre las llamas, mientras hay entre sus piernas una salamandra. En el epigrama muestra la diferencia, en una misma situación ante una dama, entre un hombre que se entrega a la pasión, representado por el sátiro, y otro que muestra un amor más noble y que se simboliza por la salamandra, a la que dedica la glosa, donde menciona la idea que se tiene sobre ella, de que vive en el fuego. Juan de Horozco en el emb. III, 33, también se sirve de la figura de un sátiro y el fuego para representar el fuego del amor. Covarrubias en la cent. III, emb. 29 pinta a un galán y una dama en la corte y entre los dos una chimenea con fuego con la advertencia en el mote "Nec prope nec longius» (ni cerca ni muy lejos), que es la manera que debe adoptar el caballero en la corte con respecto a las damas.

En la cent. III, emb. 63 [fig. 19], en el grabado, según se expresa al final de la glosa, aparece una hornaza de fuego, que tiene encima un corazón con muchas flechas, mientras Cupido está soplando con unos fuelles, y encima el lema «Tot sunt in amore dolores» (tantas son en el amor las penas), tomado de Ovidio, Arte de Amar II, 519. En el epigrama se refiere a la mujer hechicera que ejerce sus artes para que el hombre consienta ante la mujer que lo ama, pero ésta no repara en que el amado pueda morir, si no consiente; además, aunque consienta el enamorado, el amor le va a dar mil dolores. En la glosa insiste en el arte de la hechicera y considera lo que ésta hace para afligir al hombre que huye de la amistad de una mujer --clavar un corazón de cera con muchas agujas, diciendo ciertas palabras, que hacen el efecto-- como una superstición y piensa que es una mentira y un embuste; asimismo, señala que si de la acción de la hechicera surge algún efecto, éste es debido a la acción del diablo, con el que tienen pacto este tipo de mujeres, si bien permitiéndolo dios. Al referirse a que los enamorados dicen muchas exageraciones y encarecimientos, entre ellos el que tiene el corazón atravesado por mil flechas, cita a Propercio y Terencio. 


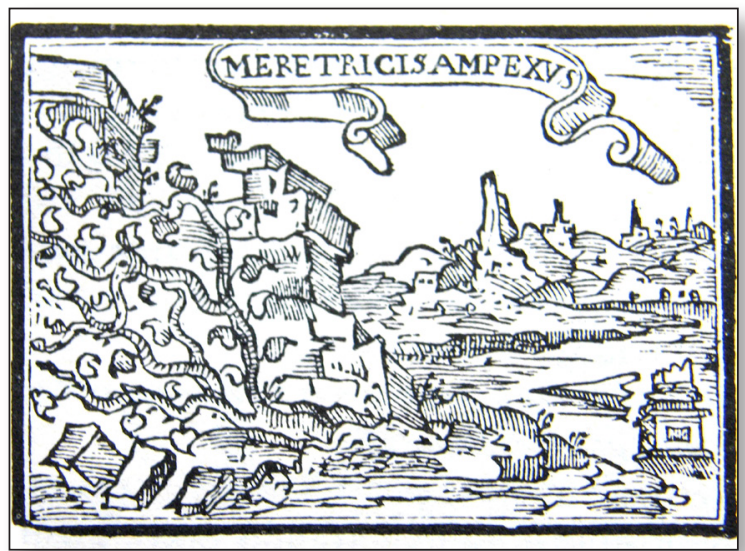

Fig. 20. Sebastián de Covarrubias, Emblemas morales. Cent. I, emb. 37 .
A la hiedra significando a la ramera dedica la cent. I, emb. 37 [fig. 20], con el lema "Meretricis amplexus» (el abrazo de la meretriz), en cuyo grabado se representa un muro y la hiedra que terminará por derrumbarlo. En el epigrama compara el daño que causa la prostituta con sus dulces caricias y halagos con el que produce la hiedra que puede secar un árbol e incluso derribar un muro. En la glosa sigue insistiendo en simbolizar con la hiedra a la ramera, ya que ésta, cuando coge a alguien entre sus brazos, que parecen amorosos, no lo deja hasta que le ha consumido honra, hacienda, salud y vida; en la segunda parte en vez de

hacer alusión al árbol, se centra en la posibilidad de que pueda la hiedra derribar un muro, señalando especialmente a los religiosos que sucumben ante las prostitutas.

Su hermano Juan de Horozco había dedicado el emblema III, 18 a este tema, presentando en la pictura a la hiedra abrazada a un árbol con el mote «Enecat amplexu» (con su abrazo mata), que es el inicio de un emblema de B. Aneau, en el que se había inspirado. Covarrubias seguirá a estos autores en la primera parte, pero se separa de ellos en lo referente al muro al que se halla asida la hiedra y su comparación con los religiosos. En la época de estos autores de emblemas, Baltasar Gracián, en El Criticón III, 8, muestra también esta metáfora con sentido negativo al señalar cómo la mujer igual que la hiedra, con su abrazo mortal, seca a un número grande y diverso de hombres significados por los árboles.

En las fuentes latinas podemos encontrar los pensamientos que hallamos en estos emblemas; en Plinio el Viejo, Historia Natural XVI, 34, se documenta el hecho de que la hiedra ahogue a un árbol o derribe a un muro sobre los que se apoya. Horacio significa a la prostituta con la hiedra en dos composiciones con el aspecto negativo que se observa en los libros de emblemas, así en Odas I, 36, 17-20, y Epodos XV, 5-6. Con anterioridad a estos autores, ya en el siglo I a. de C., Catulo usa esta metáfora, pero sin valor negativo; en el poema 61, un epitalamio o canto de bodas, simboliza la feliz unión por el matrimonio del hombre y la mujer, y en este mismo poema también se sirve de la metáfora de la vid y el olmo para representar también esa unión feliz de los esposos, que se ha visto antes en su poema 62. En el siglo IV en una composición del mismo género que las anteriores de Catulo, los Versos fesceninos

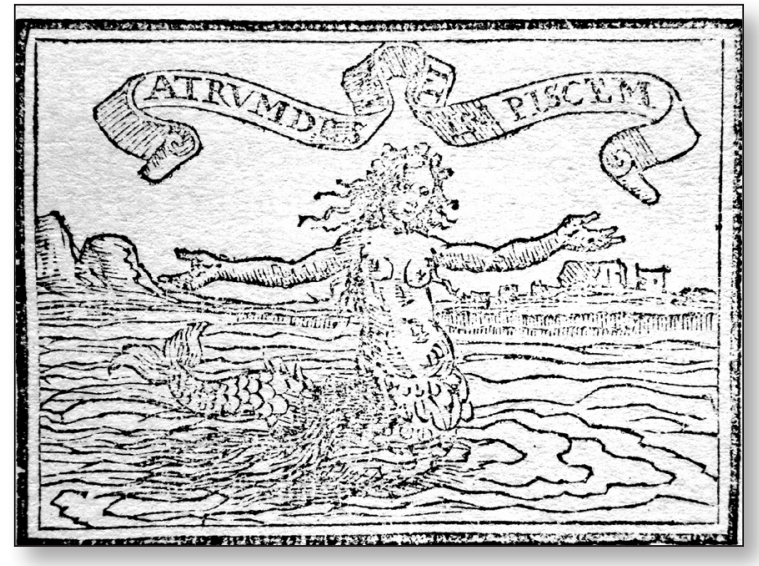

Fig. 21. Sebastián de Covarrubias, Emblemas morales. Cent. I, emb. 94. 
dedicados por Claudio Claudiano a Honorio y María con motivo de su boda, se recogen estas mismas metáforas para mostrar la unión dichosa de los cónyuges.

En la cent. I, emb. 94 [fig. 21], es la sirena, ser fabuloso con gran tradición, la que le sirve también para significar a la ramera. En el dibujo pinta a una sirena mitad mujer y mitad pez con el lema "Atrum desinit in piscem» (termina en negro pez) que toma de Horacio, Arte poética 3-4. En el epigrama identifica al vicio de la carne con una dama de medio cuerpo por arriba muy hermosa y de medio para abajo pez de dura escama, coincidente con lo que hay en el grabado. En la glosa en primer lugar señala que en muchos lugares de las sagradas escrituras se exhorta a los hombres a huir de la ramera, para señalar luego que en el emblema él la representa con figura de sirena, la cual con halagos, blanduras y suave canto atrae a los hombres, a los que privándoles de juicio y sentido, finalmente los mata. Termina diciendo que como es un lugar común tratado por muchos no va a presentar ninguna autoridad ni testimonios eclesiásticos o profanos para confirmarlo. Su hermano dedica a este tema el emblema II, 30 con un grabado donde aparece también una sirena; en el epigrama se hace mención a cómo el placer se presenta al principio de forma agradable, pero finaliza de forma dañosa. Ya Andrea Alciato realizó el emblema 115 con este tema; en el dibujo se ve a Ulises atado al mástil de su barco, con una serie de restos humanos a su alrededor, y tres sirenas, una con una lira, otra con una flauta, y la tercera cantando. En el epigrama hace tanto alusión a la sirena mitad mujer y mitad ave, que es la que aparece en la antigüedad, como a la sirena mitad mujer mitad pez, que se ha generalizado en nuestros días. En dicho epigrama recoge también el texto de Horacio que sirve de lema a Covarrubias. Termina diciendo que las prostitutas no tienen nada que hacer con los doctos como tampoco nada pudieron hacer las sirenas con Ulises.

\section{MUJER Y BELLEZA}

La belleza es en general uno de los aspectos siempre tratados en relación con la mujer, incluyendo en particular a veces el uso de afeites o cosméticos; así en Roma, en la época de Augusto, Ovidio, autor que proporciona el mayor número de fuentes para los emblemas de Covarrubias, además de lo que enseña a las mujeres en lo referente a su arreglo y comportamiento para seducir a los hombres o separarse de ellos en su Arte de amar y en sus Remedios contra el amor, respectivamente, les dedica, aunque breve y de la que sólo nos ha llegado una parte, otra obra denominada Cosméticos para el rostro femenino; en ella al inicio, al justificar este escrito, les dice que aprendan los cuidados que realzan el rostro y los medios para mantener la belleza, no considerando un delito el refinamiento, si bien estima inútiles los procedimientos mágicos y cree que las cualidades del espíritu son las principales, ya que la belleza es destruida por el paso del tiempo y pronto el rostro es surcado por las arrugas. Los autores cristianos en general se muestran contrarios al arreglo de las mujeres y entre ellos podemos señalar a Tertuliano. ${ }^{19}$ En la época de nuestro autor, Fray Luis de León en su obra sobre La perfecta casada se refiere de forma significativa al uso de afeites o cosméticos y otras formas de arreglo de la casada y la belleza natural, mostrándose enemigo de los afei-

19. Escribió la obra De cultu feminarum sobre los adornos de la mujer. Otro autor a destacar es san Jerónimo, que en su Epistolario da sus opiniones sobre el tema. 


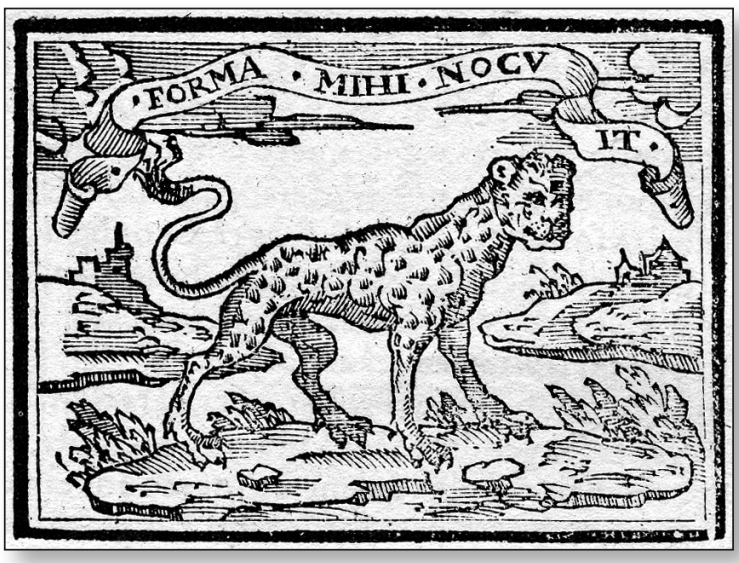

Fig. 22. Sebastián de Covarrubias, Emblemas morales. Cent. II, emb. 62 .

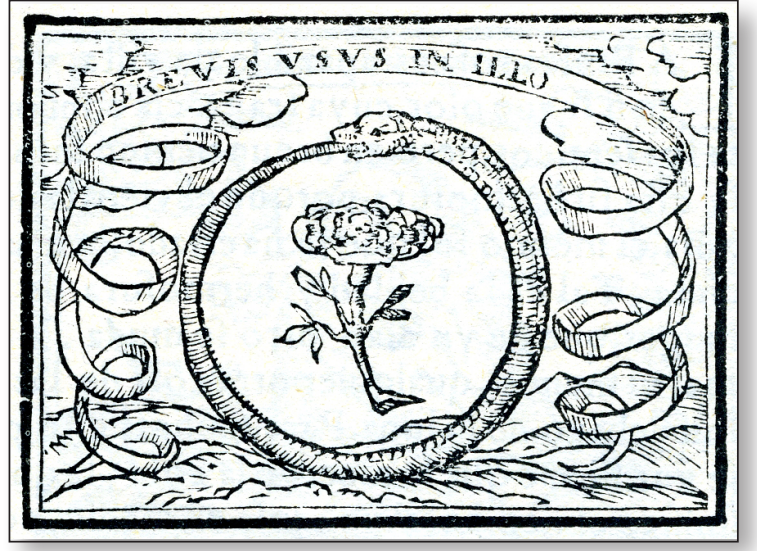

Fig. 23. Sebastián de Covarrubias, Emblemas morales. Cent. II, emb. 3. tes o arreglos de las mujeres. También dedica un capítulo a los adornos Juan Luis Vives. ${ }^{20}$

Sebastián de Covarrubias dedica varios emblemas al tema de la belleza y el arreglo de la mujer, donde se acerca al tratamiento que hace Ovidio, y lo presenta de tal manera que en parte se podría aplicar a nuestra época actual, con los excesos de la cirugía estética.

En la cent. II, emb. 62 [fig. 22], en la pictura se halla una pantera como símbolo de la mujer hermosa, con el lema «Forma mihi nocuit» (mi belleza me perjudicó), que toma de Ovidio, Metamorfosis II, 572, donde se refiere a Aglauros, cuya belleza atrajo al dios del mar, cuando caminaba por la playa, y para huir de él se convirtió en ave. En el epigrama considera la hermosura como un bien apreciado en todas las cosas, pero sobre la mujer insiste en que ha de ser recatada para impedir que su belleza le sirva de perjuicio. El significar a la mujer hermosa por la pantera o por el lince, según la glosa, es por la vistosidad de la piel de estos animales que hace que sean cazados para robársela.

En la cent. II, emb. 3 [fig. 23], nuestro autor se sirve de la rosa para significar a la mujer bella que pone en ello su contento, advirtiéndole que le sucederá como a la rosa que hoy está

alegre y fresca, pero mañana marchita muere. En el grabado se representa a una rosa dentro del ouroboros, o como se dice en la glosa «una sierpe que se muerde la cola, la cual significa el tiempo, y una rosa en medio, por lo que él gasta y consume». Tanto en el epigrama como en la glosa insiste en comparar la belleza de la rosa y su breve duración con el encanto y hermosura de la mujer que de un día a otro se muda.

La cent. II, emb. 93 [fig. 24], con el mote vulgar «Esto y más por remozarme» y un grabado con una culebra saliendo de un estrecho resquicio entre piedras, lo dedica a la mujer que intenta disimular su edad. En el poema expresa como la mujer que ya no es lo que era, se aprovecha de exquisitos martirios para mantener su hermosura, poniendo en peligro su salud y su vida. Hace una comparación con la culebra que pierde su piel, buscando para ello una estrecha hendidura, presentando en la glosa dos citas, una de Ovidio, Arte de amar II,

20. La formación de la mujer cristiana, capítulo VIII, donde sigue las ideas de los autores cristianos.

IMAGO, NÚM. 10, 2018, 53-73 


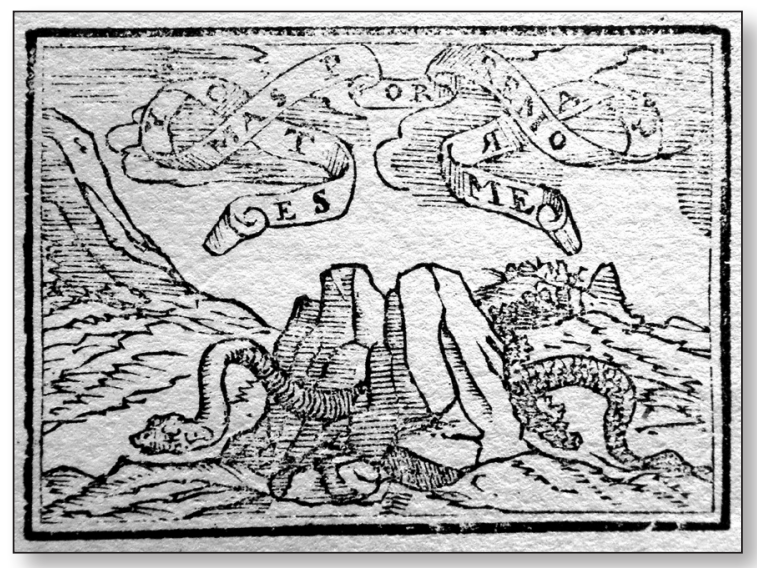

Fig. 24. Sebastián de Covarrubias, Emblemas morales. Cent. II, emb. 93.

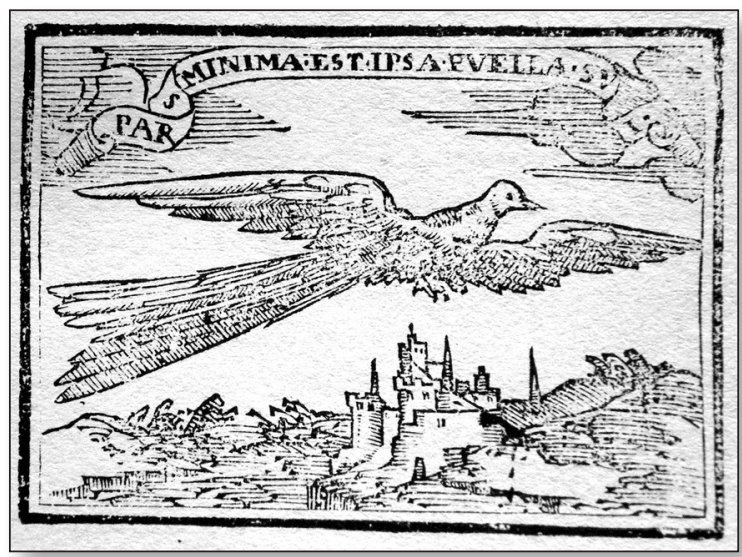

Fig. 25. Sebastián de Covarrubias, Emblemas morales. Cent. III, emb. 72.
275, donde se cuenta que las mujeres arreglan con refinamiento los desperfectos de los años para conseguir con sus cuidados no parecer viejas y otra de Virgilio, Eneida II, 469-472, en la que se hace alusión a que la culebra pierde su piel a la vez que su vejez.

La idea de que la mujer usa una serie de productos nocivos para la salud con la intención de parecer hermosa se halla también en fray Luis de León, que además exhorta a la mujer a mostrarse tal como es, sin recurrir a artificios que le hagan aparentar lo que no es. Esta última idea tiene cierta relación con lo que Sebastián de Covarrubias expresa en el emblema III, 72 [fig. 25] con el mote "Pars minima est ipsa puella sui» (la joven es la parte más pequeña de sí misma), que toma de Ovidio, Remedios contra el amor 346, donde recomienda al amante no correspondido visitar a su amada por la mañana, cuando todavía no se ha acicalado, ya que en realidad lo que seduce al hombre son las galas, pues, según dice, con piedras preciosas y oro todo se tapa y la joven es la parte más pequeña de sí misma. En la pictura presenta el ave del paraíso volando con su gran plumaje y en el epigrama, una vez pelada, la compara con la mujer que pierde su encanto "sin chapín, verdugado y destocada». ${ }^{21}$

\section{CONCLUSIONES}

El retrato que nos presenta se corresponde, como era de esperar, con el de una mujer de su época, identificándose con el tipo de mujer que desde muy antiguo se da en sociedades de tipo patriarcal, pero es importante observar cómo hace una serie de acotaciones que mues-

21. En su Tesoro de la lengua, en la voz chapín, Covarrubias lo define como un tipo de calzado para las mujeres, consistente en varios corchos; en la voz verdugo dice que verdugado es una saya a modo de campana, toda de arriba abajo guarnecida con unos ribetes que por ser redondos como los verdugos de los árbol y por ventura de color verde es llamado así. 
tran que Sebastián de Covarrubias está muy cercano a la sociedad de su época y se fija en circunstancias particulares, que le acercan a la vida real. ${ }^{22}$ Por otro lado, como también suele ser habitual en otro tipo de fuentes, se refiere especialmente a las capas altas de la sociedad. En relación con la mujer en general, aunque la muestra como un mal, según la creencia tradicional, no obstante hace objeciones a ello y, a pesar de considerarla sometida al varón, también menciona que ha realizado acciones importantes en distintas actividades. Por otro lado, también documenta a una mujer muy peculiar de su época, la barbuda de Peñaranda.

La presencia más importante es la de la mujer casada; en la doncella los temas que trata se relacionan fundamentalmente con el matrimonio; aparte de la loa a la virginidad, el tema del rapto sin duda lleva a la realidad de la época con matrimonios en los que no se tienen en cuenta la voluntad de la familia, importante para la política matrimonial que se desarrolla entre las familias sobresalientes del momento. Con respecto a la mujer casada, se refiere a la fidelidad que la mujer debe al marido, pero también insiste en el trato que éste debe a la mujer, insistiendo en que debe tratarla bien, aunque se basa en los daños que puede causar la mujer, si se le maltrata. Asimismo, es importante el hecho de que alude al matrimonio con sus cargas, incluyendo a ambos cónyuges. En relación con la maternidad hay que destacar que menciona fundamentalmente a los hijos habidos fuera del matrimonio, y si censura a la mujer que atribuye a su hijo por conveniencia un padre, que no lo es, también critica al padre que abandona al hijo, el cual sufre las consecuencias de tal abandono. Al referirse a la educación de los hijos menciona tanto a los padres como a las madres; se opone a una educación muy regalada, especialmente en este aspecto cita a las madres, y es partidario de que se despeguen de los padres y tengan casa propia e, incluso, que salgan fuera a otros lugares.

Con respecto a las relaciones habidas fuera del matrimonio, muestra al varón el daño que un amor pasional puede traerle, mencionando a la hechicera que con sus artes --que Covarrubias considera una superstición-- procura atraerlo hacia una mujer que va a causarle una serie de daños. En los emblemas que dedica a la figura de la prostituta no censura a la mujer en sí, sino que se dirige a los varones, en un caso especialmente a los religiosos, para que las eviten por las consecuencias perjudiciales que el trato con ellas puede acarrearles, tanto en el aspecto económico como en la salud.

Terminamos con un capítulo dedicado a la belleza, donde ésta, según Covarrubias, es un bien preciado en general, no obstante, advierte a la mujer que debe ser cautelosa, ya que la excesiva belleza le puede perjudicar. Nos parece cercano cuando habla de los excesos que puede hacer una mujer para parecer joven cuando va dejando de serlo. La fuente principal para este apartado es especialmente Ovidio, que también lo es en general para todos los emblemas morales.

\section{BIBLIOGRAFÍA}

Agudo Romeo, M. del M. [2004]. «La mujer en los Emblemata Moralia (Agrigento, 1601) de Juan de Horozco", en S. López PozA (ed.), Florilegio de estudios de emblemática. Actas del IV Congreso Internacional de Emblemática, A Coruña, Sociedad de Cultura Valle Inclán, 109118. 
Agudo Romeo, M. del M. [2009]. "Animales, monstruos y plantas, símbolos de la mujer en la literatura emblemática», en M. T. Muñoz García de Iturrospe (ed.), Antiguos y modernos. Presencias clásicas, de la antigüedad al siglo XXI, Bilbao, Universidad del País Vasco, 175-216. Agudo Romeo, M. del M. [2010]. «Fuentes literarias en prototipos femeninos de la emblemática», en Humanismo y pervivencia del mundo clásico, Alcañiz-Madrid, Instituto de Estudios Humanísticos, Consejo Superior de Investigaciones Científicas, vol. IV, 5, 2777-2789.

Agudo Romeo, M. del M. [2011]. "Cuestiones matrimoniales en libros de emblemas", en R. Zafra y J. J. AzAnza (eds.), Emblemática trascendente, hermenéutica de la imagen, iconología del texto, Pamplona, Sociedad Española de Emblemática, 103-118.

Alciato, A. [1985]. Emblemas, edición y comentario de S. Sebastián, prólogo de A. Egido y traducción de P. Pedraza, Madrid, Akal.

Antón, B. [2002]. «Emblemática y didáctica del latín. Insignis pietate Ciconia», Revista de Estudios Latinos, 2, 199-233.

Ariosto, L. [2002]. Orlando furioso, T. I, edición bilingüe de C. Segre y M. M. MuÑIz, Madrid, Cátedra.

Ausonio [1990]. Obras, traducción y notas de A. Alvar, Madrid, Gredos.

Catulo, V. G. [1982]. Poesías, texto revisado y traducido por M. Dolç, Madrid, Consejo Superior de Investigaciones Científicas.

Claudiano, Poemas, introducción, traducción y notas de M. Castillo, Madrid, Gredos.

Claudio Eliano [1984]. Historia de los animales, introducción, traducción y notas de J. M. Díaz-Regañón, Madrid, Gredos.

Covarrubias, S. de [1978]. Emblemas morales, edición e introducción de C. Bravo-Villasante, Madrid, Fundación Universitaria Española.

Covarrubias Horozco, S. de [2006]. Tesoro de la lengua castellana o española, edición integral e ilustrada de I. Arellano y R. Zafra, Madrid, Universidad de Navarra, Editorial Iberoamericana.

Gracián, B. [2016]. El Criticón, edición de L. Sánchez Laílla y J. E. Laplana, anotación de M. P. Cuartero, J. E. Laplana y L. Sánchez Laílla, Zaragoza, Institución Fernando el Católico.

EgIDo, A. [1982]. "Variaciones sobre la vid y el olmo en la poesía de Quevedo: amor constante más allá de la muerte», en Homenaje a Quevedo, Salamanca, vol. II, 213-232.

Escalera Pérez, R. [2000]. "Monjas, madres, doncellas y prostitutas. La mujer en la emblemática», en V. Mínguez (ed.), Del libro de emblemas a la ciudad simbólica. Actas del III Simposio Internacional de Emblemática Hispánica, Castellón, vol. II, 769-791.

Escalera Pérez, R. [2013]. "Mulier fortis. Jeroglíficos, símbolos y alegorías en las exequias de las reinas en Granada y Sevilla (siglos VII y XVIII) ", en A. MARTínez, I. OsunA y V. InfanTES (eds.), Palabras, símbolos, emblemas. Las estructuras gráficas de la representación, Madrid, Turpin editores, Sociedad Española de Emblemática, 245-256.

García Arraz, J. J. [1996]. Ornitología emblemática: las aves en la literatura simbólica ilustrada en Europa durante los siglos XVI y XVII, Cáceres, Universidad de Extremadura.

García Arraz, J. J. [2005]. "Vxuriae virtutes: la imagen de la mujer virtuosa y su contexto en la cultura simbólica de la Edad Moderna», en J. L. DE LA Montaña e I. Rodríguez (eds.), De la intimidad y el susurro al poder, Cáceres, Junta de Extremadura, 49-116.

García Arraz, J. J. [2010]. Symbola et emblemata avium. Las aves en los libros de emblemas y empresas de los siglos XVI y XVII, A Coruña, SIELAE y Sociedad de Cultura Valle Inclán.

Hernández Miñano, J. de D. [2015]. Emblemas morales de Sebastián de Covarrubias: iconografía y doctrina de la Contrarreforma, Murcia, ediciones de la Universidad de Murcia.

Horacio [2002]. Sátiras, Epístolas y Arte Poética, ed. bilingüe de H. Silvestre, Madrid, Cátedra. 
Horacio [2004]. Odas y epodos, edición bilingüe de M. Fernández-Galiano y V. Cristóbal, Madrid, Cátedra.

Horozco y Covarrubias, J. [1604-1605]. Emblemas morales, Zaragoza.

Horozco y Covarrubias de Leyva, J. de [2017]. Trescientos emblemas morales, Estudio y traducción de M. del M. Agudo, A. Encuentra y J. F. Esteban, Zaragoza, Prensas Universitarias de Zaragoza.

Isidoro de Sevilla [1993]. Etimologías, ed. bilingüe de J. Oroz y M. A. Marcos, Madrid, Biblioteca de Autores Cristianos.

León, Fray L. de [1987]. La perfecta casada, Madrid, Taurus.

Livio, T. [1987]. Historia de Roma desde la fundación de la ciudad (Ab urbe condita), Libros I y II, texto revisado, traducción y notas de A. Fontán, Madrid, Consejo Superior de Investigaciones Científicas.

López Poza, S. [2002]. "La emblemática en El Criticón de Baltasar Gracián», en A. Bernat y J. T. Cull (eds.), Los días del Alción. Emblemas, Literatura y Arte del Siglo de Oro, Barcelona, Medio Maravedí, 353-373.

Mínguez, V. [2010]. "Matrimonio y emblemática: el rito de la dextrarum iunctio y la representación de los enlaces nupciales en la casa de Austria», en I. Arellano y A. Martínez (eds.), Emblemática y religión en la península Ibérica (Siglo de Oro), Universidad de Navarra, Iberoamericana, Vervuert, 259-282.

Ovidio Nasón, P. [1964-1984]. Metamorfosis, texto revisado y traducido por A. Ruiz De Elvira, Barcelona, Alma Mater, Consejo Superior de Investigaciones Científicas, 3 vols.

Ovidio Nasón, P. [1986]. Heroidas, texto revisado y traducido por F. Moya, Madrid, Consejo Superior de Investigaciones Científicas.

Ovidio Nasón, P. [1995]. Amores, Medicamina faciei feminae, Ars amatoria, Remedia amoris, edición de E. J. Kenney, Oxford.

Ovidio Nasón, P. [2005]. Arte de Amar. Remedios contra el amor. Cosméticos para el rostro femenino, edición de E. Montero, Madrid, Akal.

Peñasco GonzÁlez, S. M. [2015]. Edición filológica y estudio de 'Emblemas morales' de Sebastián de Covarrubias Orozco (1610), Tesis Doctoral, A Coruña, Universidad da Coruña.

Plinio [2003]. Historia Natural, libros VII-XI, traducción y notas de E. del Barrio y otros, Madrid, Gredos.

Plutarco [2010]. Preceptos conyugales, traducción de F. Gutiérrez, Palma de Mallorca, José J. de Olañeta.

Rodríguez Moya, I. [2010]. «Epitalamios e himeneos. Iconografía y literatura nupcial en las cortes del Barroco", Imago. Revista de emblemática y cultura visual, 2, 8-24.

Rodríguez Moya, I. [2011]. "Iconografía de la ceremonia nupcial y el matrimonio en la cultura simbólica europea», en R. Zafra y J. J. Azanza (eds.), Emblemática trascendente, hermenéutica de la imagen, iconología del texto, Pamplona, Sociedad Española de Emblemática, 729-748.

Soto, H. de [2017]. Emblemas moralizadas, edición y estudio de J. J. García Arranz y N. Pena SueIro, Palma de Mallorca, José J. de Olañeta.

Virgilio [2000]. Eneida, traducción y notas de J. de EchaVe-Sustaeta, Madrid, Gredos.

Virgilio [2000]. Bucólicas, edición bilingüe de V. CRistóbal, Madrid, Cátedra.

VIVES, J. L. [1994]. La formación de la mujer cristiana, traducción, introducción y notas de J. Beltrán, Valencia, Ayuntamiento de Valencia.

Vives, J. L. [1994]. Los deberes del marido, traducción, introducción y notas de C. BernaL, Valencia, Ayuntamiento de Valencia. 
